\title{
11 TEMAS POLÊMICOS NA OBRA "SAPATO DE SALTO" DE LYGIA BOJUNGA: UMA EXPERIÊNCIA PRÁTICA DE INCENTIVO A LEITURA E PROTAGONISMO JUVENIL
}

\author{
TWELVE POLITICAL ISSUES ON "SAPATO DE SALTO" BY LYGIA BOJUNGA: A PRACTICAL \\ EXPERIENCE TO ENCOURAGE READING AND YOUNG LEADERSHIP
}

Taynara Alcântara Cangussú

\footnotetext{
1 Mestra em Letras e docente EBTT do Instituto Federal do Paraná, Campus Paranavaí. tay.nara.alcantara@hotmail.com
}

CANGUSSÚ, T. A. 11 Temas polêmicos na obra "sapato de salto" de Lygia Bojunga: uma experiência prática de incentivo a leitura e protagonismo juvenil. Akrópolis, Umuarama, v. 29, n. 2, p. 201-208, jul./dez. 2021.

\section{DOI: $10.25110 / a k r o p o l i s . v 29 i 2.8566$}

Resumo: Para acompanhar as diversas transformações sociais e culturais do cenário contemporâneo, a escola têm sentido a necessidade de abordar temas considerados polêmicos. Nesse cenário, a literatura tem se mostrado como importante instrumento para atender a essa demanda. Este trabalho objetiva justamente apresentar uma prática docente na qual se usou a obra "Sapato de Salto", de Lygia Bojunga (catalogada como literatura infanto-Juvenil e disponibilizada pelo programa PNLD literário) para abordar 12 temas ainda considerados polêmicos e/ou tabus. A saber: (1) abuso sexual infantil; (2) Exploração do trabalho infantil; (3) descoberta da sexualidade e homoafetividade; (4) Suicídio; (5) protituição; (6) saúde mental; (7) machismo; (8) Empoderamento Feminino; (9) Dependência Emocional; (10) Gravidez na Adolescência; (11) visões de mundo conservadora e liberal. O trabalho foi organizado por meio de um evento intitulado "Rodas de Conversas sobre o livro Sapato de Salto", criado por uma professora da Rede Federal de ensino na plataforma even3. Após montarem um handout com pesquisas científicas sobre os temas e terem feito uma breve análise da obra focando em cada temática, 120 alunos de três turmas do primeiro ano do Ensino Médio convidaram a comunidade para se inscreverem no evento e protagonizaram discussões sobre as temáticas. Durante a atividade, os alunos ressaltaram a importância de espaços para discussões sobre esses temas e propuseram a criação de novos projetos e atividades relacionados às temáticas. No geral, a atividade nos fez observar que ações como essa vão ao encontro com os objetivos da BNCC e de outros documentos oficiais, pois, além de estimular o protagonismo juvenil, é um passo importante na formação do estudante como leitor e cidadão.

Palavras-Chave: Literatura Infanto-Juvenil; Protagonismo Juvenil; Temas polêmicos.

ABSTRACT: In order to be abreast of the various social and cultural transformations in the contemporary scenario, the school has felt the need to address issues considered controversial. Within this scenario, literature has been regarded as an important instrument to meet this demand. This work aims precisely at presenting a teaching practice in which the work "Sapato de Salto" by Lygia Bojunga (cataloged as children's literature and made available by the PNLD literary program) 
was used to address 11 topics still considered controversial and/or taboo. Namely: (1) child sexual abuse; (2) exploration of child labor; (3) uncovered sexuality and homo-affectivity; (4) suicide; (5) prostitution; (6) mental health; (7) machoism; (8) female empowerment; (9) emotional dependence; (10) pregnancy at adolescence; (11) conservative and liberal views of the world, and (12) prostitution. The work was organized through an event entitled "Talk Sesions on the Sapato de Salto book" created by a teacher at the Federal Education Network on the even3 platform. After assembling a leaflet with scientific research on the topics, and after a brief analysis of the work focusing on each topic, the 120 students from three first-year classes in the Secondary Education invited the community to enroll in event and engage in discussions on the topics. During the activity, the students emphasized the importance of spaces to discuss these topics and proposed the creation of new projects and activities related to the topics. Generally speaking, it could be observed that actions such as these meet the objectives of the BNCC and other official documents, since they not only encourage youth leadership but are also an important step in the training of the student as an effective reader and citizen.

KeYwords: Children's and Youth Literature; Youth Leadership; Controversial topics.

\section{INTRODUÇÃO}

As transformações sociais das últimas décadas, especialmente nas configurações familiares, gerou mudanças nos valores socioculturais e também nas concepções de infância e juventude. Essas mudanças fizeram surgir pontos de conflito/ tensão que se materializam em temas, que necessitam serem discutidos nas escolas, mas podem ser considerados "difíceis" ou "polêmicos", conforme entendem Kirchof e Souza (2019).

Nas últimas décadas, esses temas passaram a ser abordados em obras de literatura infantojuvenil, fato que as torna instrumento importante para que educadores os discutam na escola como parte do trabalho de formação humana e cidadã. Uma dessas obras é "Sapato de Salto", de Lygia Bojunga.

De modo geral, "Sapato de Salto" retrata parte da vida de dois pré-adolescentes que passam por e/ou entram em contato com conflitos de quase toda ordem (sexuais, psicológicos, familiares, etc.). Tal fato torna essa obra um campo fértil para a abordagem de temas que podem ser considerados polêmicos.

Após receber 120 exemplares dessa obra na escola onde leciona, uma professora decidiu trabalhar com ela em três turmas do primeiro ano do Ensino Médio. Para tanto, foram levantadas duas questões que nortearam seu trabalho: (a) quais temas possivelmente difíceis/ polêmicos a obra permite trabalhar? e (b) como abordá-los em um projeto didático-pedagógico que priorize o respeito e a humanização desses temas em prol de uma formação cidadã e, ao mesmo tempo, fortaleça o protagonismo juvenil?

Essas questões delinearam um projeto didático pedagógico que foi colocado em prática, em 2019. Os resultados desse projeto motivaram a escrita deste artigo que tem por objetivo: (a) apresentar os temas levantados para discussão com os alunos e (b) fazer um relato da prática que deu vida a esse projeto.

Para cumprir com esses objetivos, organizamos o texto em três partes: na primeira, fazemos um breve apanhado teórico sobre o que a literatura entende por temas polêmicos e sobre sua importância nas práticas pedagógicas; na segunda, listamos os temas supostamente polêmicos abordados na obra; na terceira, fazemos uma descrição da prática pedagógica (o que dá, a este artigo, um tom de relato de experiência); na última, por fim, fazemos algumas considerações finais.

\section{TEMAS DIFÍCEIS/ POLÊMICOS LITERATURA INFANTO-JUVENIL}

Segundo Kirchof e Souza (2019, p. 28), "a ideia de que um tema é difícil ou até mesmo inadequado para ser abordado em livros para crianças está diretamente relacionada à concepção que se tem, em determinado contexto sociocultural, do que seja infância e juventude". No Brasil, apesar de ser recente o próprio surgimento dos conceitos de infância e juventude, desde o nascimento, já passaram por uma série de mudanças.

Henick e Faria (2015) fazem uma retomada histórica do conceito de infância no Brasil e mostram que essas transformações sempre estiveram relacionadas à classe social a qual a criança pertence. Exemplo disso são os motivos que levaram à necessidade de educação para crianças: enquanto os filhos de ricos tinham de ser educados para levar adiante os negócios familiares, os dos pobres tiveram suas primeiras experiências pedagógicas em casas que recebiam crianças abandonadas.

Grossman (2010, p. 47) atém-se às mudanças históricas no conceito de adolescência e 
destaca que elas envolvem "dissolução de certezas e um estado de desamparo coletivo, que implicam uma experiência complexa e plural".

Em ambos os casos, é possível perceber o quanto os conceitos de infância e juventude foram/têm sido incutidos de complexidades. A literatura infanto-juvenil, contudo, por muito tempo ignorou essas complexidades, tendo em vista que, especialmente em tempos anteriores à década de 70, devido a seu vínculo com a burguesia e com a escola, lançava seus esforços para ornamentar valores morais e arquitetar funções didáticos e pedagógicas que atendiam às demandas escolares.

Martha (2011) lembra que Ceccatini (2000) foi um dos pesquisadores que fez um dos maiores estudos sobre obras de autores nacionais de literatura infanto-juvenil. Nesse estudo, conclui que, entre 1955 e 1975, houve uma mudança nas características dos textos de literatura infantojuvenil:

somente depois de toda a análise realizada ao longo desta pesquisa parece ser possível afirmar com segurança que, se a literatura juvenil brasileira comungou duas décadas atrás do caráter pedagogizante [...], hoje existe um conjunto de obras significativo em que isso não ocorre, afirmando a autonomia do subgênero (CECCANTINI, 2000: 433 apud MARTHA, 2011, p. 02)

Conforme analisa o autor, as obras de literatura infanto-juvenil passaram por muito tempo restritas à função de ensinar, seja conteúdos morais ou escolares, no entanto, atualmente, ela ganhou autonomia. Essa autonomia, segundo Martha (2011, p. 02), forma-se, principalmente, pela mudança nas temáticas, que deixaram essa preocupação meramente pedagógica e moralizante e passaram a ser mais "atraentes aos jovens leitores, com linguagem muito próxima à do uso cotidiano". A autora destaca que:

Com linguagem questionadora de convenções e normas, técnicas mais complexas de narrar, as obras contemporâneas tratam de assuntos anteriormente proibidos a leitores mais jovens - morte, separações, violência, crises de identidade, escolhas, relacionamentos, perdas, sexualidade e afetividades (MARTHA, 2011, p. 02 grifos nossos).
Como é possível observar, a autora chama atenção para o fato de as obras de literatura-infanto juvenil contemporâneas tratar de temas complexos que, embora reais e urgentes na vida de grande parte das crianças e adolescentes, são censurados e considerados "proibidos". Talvez, porque ainda pairam concepções sociais de infância e juventude que permanecem próximas a noção - assumida em um passado próximo pela burguesia - de que as crianças são apenas fontes de graça, ingenuidade e divertimento.

Esses temas, chamados por Martha (2011) de "proibidos" são conceituados por Kirchof e Souza (2019, p. 30) como temas "difíceis" ou "polêmicos". Os autore explicam que temas como "morte", "sexo", dentre outros, tornam-se "proibidos" e/ ou "difíceis" e/ou "polêmicos", porque, pode haver "assimetria entre os códigos de recepção e de produção das obras voltadas para o público infantil". Isso significa dizer que a representação que os autores da obra tem sobre o que é criança e adolescente pode não ser a mesma de seu leitor. Um leitor, por exemplo, que concebe a criança como repleta de graça e fantasias e o jovem como um mero aspirante à vida adulta, talvez não receberia de forma afirmativa uma obra que abordasse, por exemplo, prostituição e homoafetividade na infância e, então, esses temas passariam a ser considerados polêmicos.

No geral, a escola enfrenta bastantes dificuldades de abordar temas como esses, mas, ao mesmo tempo, considera necessário fazêlo, visto que lida com sujeitos cada vez mais complexos, oriundos de realidades cada vez mais diversas e que precisam da escola como um espaço de formação humana e social e também como um lugar para que eles possam descobrir suas identidades. Documentos oficiais, como os Parametros Circulares Nacionais destacam a necessidade de abordar temas potencialmente polêmicos, como os relacionados à sexualidade. $\mathrm{Na}$ prática escolar, uma das formas de abordar esses temas é utilizando a literatura.

Uma das primeiras autoras a abordar temas como esses na literatura infanto-juvenil foi Lygia Bojunga, na obra "Os Colegas", a qual conta, de forma divertida, a história de vários animais que vão para rua por conta de algum conflito anterior (um por conta do abandono dos donos, outros por serem "vira-latas", outro porque não se acostumou com a vida luxuosa dos donos, etc.) e encontram na amizade a vontade de viver. Nessa narrativa, Bojunga transcende "os limites entre a realidade e 
a fantasia (...) e proporciona à criança um caminho para a maturidade e para a busca da sua identidade (CRISTÓFANO, 2009, p. 02)".

Esse estilo da autora permanece em obras como "A bolsa Amarela", 1976, "A casa da Madrinha", 1978, e, mais recentemente, "Sapato de Salto", 2006, a obra de que tratamos neste artigo.

De modo geral, pode-se dizer que, assim como as outras obras da autora, Sapato de Salto também aborda, por meio de um estilo que mistura fantasia e realidade, "temas da nossa sociedade, despidos do discurso moralista e utilitário (SILVA, 2013, p.01)". Um dos objetivos deste artigo é justamente fazer um levantamento desses temas e são eles que apresentamos na seção que segue.

\section{TEMAS POLÊMICOS EM "SAPATO DE SALTO", DE LYGIA BOJUNGA}

À luz do entendimento de Kirchof e Souza (2019) sobre o que seja um tema polêmico, fizemos uma análise da obra "Sapato de Salto", de Lygia Bojunga e identificamos 11 temas que consideramos ter potencial para serem polêmicos e que julgamos importantes para serem discutidos com adolescentes na escola. Expô-los-emos a seguir:

\section{TEMA 1: Abuso sexual infantil}

Esse tema é um dos principais e primeiros a serem abordados na obra. Já no primeiro capítulo, ele aparece quando a personagem protagonista, Sabrina, uma menina de apenas onze anos, é abusada por Seu Gonçalves. O trecho a seguir descreve o momento em que o ato acontece: "Não faz isso, Por favor! Não faz isso! - Tremia, suava. Não faz isso! Fez.".

Julgamos que a forma como Lygia trabalha a temática na obra pode ser extremamente eficaz para auxiliar os estudantes de Ensino Médio no processo de reconhecimento da forma como o abuso acontece, pois a autora tece a narrativa de modo a descrever o processo de construção da relação da Sabrina com Seu Gonçalves, o abusador: uma relação que começa aparentemente saudável, inocente e paternal ( "Seu Gonçalves chegou perto da Sabrina e falou em tom de segredo: - olha o que eu trouxe pra você. - humm, quanto bombom!" ) e termina de forma trágica ("Não faz isso -Fez"." E o grande segredo dos dois passou a animar a vida dele e botar sombra nos dias dela").

Mais do que apenas descrever essa trajetória (e, assim, auxiliar no reconhecimento de como um abusador constrói o processo de dominação sobre a vítima), a autora recheia sua narrativa com os efeitos psicológicos desse abuso na vida de Sabrina; fato que pode auxiliar os estudantes-leitores a entender a gravidade de um ato como esse e, no caso daqueles que já sofreram abuso, a se identificarem e buscarem sua identidade nesse processo. O trecho a seguir revela um dos momentos que Lygia mostra, por meio de linguagem bastante acessível e juvenil, as consequências psicológicas do abuso na vida de Sabrina: "foi se esquecendo de prestar atenção no estudo, foi se esquecendo de pensar que cor era isso e aquilo, nunca mais desenhou".

\section{TEMA 2: Exploração do trabalho infantil}

Junto com o abuso sexual, logo no início da obra, aparece também o tema "Exploração do trabalho infantil", posto que Sabrina foi retirada de um orfanato e levada para a casa de Seu Gonçalves e de Dona Matilde (esposa de seu Gonçalves) para cuidar dos serviços domésticos e dos filhos do casal em troca de comida e abrigo. Os trechos a seguir representam a construção desse "acordo laboral": "gosto de brincar com criança. Dona Matilde se endireitou na cadeira: - você não veio para brincar, veio para trabalhar." "Dona Matilde deu para repreender Sabrina cada vez com mais aspereza. Botou ela pra lavar prato, arear panelas, esfregar chão, limpar vidro, varrer jardim. Na hora de cuidar das crianças, Sabrina não conseguia mais vencer o cansaço $(\ldots) "$.

\section{TEMA 3: Descoberta da sexualidade e homoafetividade}

Esse tema é retratado na obra por meio do desenrolar dos conflitos e experiências dos dois personagens protagonistas: Sabrina (uma menina de onze anos, que descobre sua sexualidade por meio de um estupro e, depois, por meio da experiência da tia como Prostituta) e Andrea Doria (um menino de treze anos que vive o conflito de se descobrir homosexual em meio a um relacionamento abusivo).

A forma como Bojunga descreve essas descobertas vai desconstruindo os preconceitos comuns a certos padrões de sexualidade, pois ela constrói uma trajetória que faz o leitor entender o entorno histórico de constituição do sujeito por detrás dos "rótulos" sexuais. Exemplo disso é 
quando Sabrina se declara "puta": Sabia que eu sou puta?- ela insistiu. Deu os ombros. Se não sabia ficou sabendo, não é? (p. 168) . Apesar de parecer uma declaração muito impactante, quando inserida no contexto do livro, ela não tem tanto impacto assim. Talvez, pelo fato de o leitor entender que, por detrás dessa declaração, tem uma menina que foi abusada sexualmente, viu as outras gerações da família usar o sexo como sustento e, diante de uma situação de necessidade de se alimentar, não encontrou outra forma a não ser fazer o mesmo.

\section{TEMA 4: Suicídio}

O tema suicídio permeia toda a obra e tem seu conceito materializado na figura de uma pedra. Nos primeiros capítulos da obra, ele aparece quando Dona Gracinha, a avó de Sabrina, interage constantemente com uma pedra imaginária. Sabrina se diverte com aquilo e logo descobre que a pedra ficou marcada na cabeça doente da avó, porque sua mãe, Maristela, havia se matado ao pular em um rio com uma pedra amarrada ao pescoço. O recurso de materializar sentimentos em figuras e objetos é próprio do estilo de Bojunga e foi utilizado com maestria na obra para dar acessibilidade a um tema tão complexo e, por que não dizer: polêmico.

\section{TEMA 5: Prostituição}

Prostituição é um dos principais temas da obra e está já estampado na capa, mais especificamente, na figura de um sapato de salto, pois esse título é dado à obra a partir de um episódio em que Sabrina calça os sapatos de salto da tia morta para parecer mais velha e, assim, ter mais sucesso na busca de sustento por meio da prostituição. Dentre os inúmeros sentidos que essa imagem pode adquirir na obra, o de prostituição é o mais evidente, pois ele permeia toda a vida da Sabrina, protagonista da obra. Já no início da obra, ao final do primeiro capítulo, percebemos a temática quando Sabrina pergunta para Seu Gonçalves: "e o dinheirinho"?, fazendo um pedido em retribuição ao sexo que, após o primeiro estupro, virou cotidiano e era feito em troca de pequenos presentes, e, mais tarde, de pouca quantidade de dinheiro. Essa frase, ela proferiu após Seu Gonçalves ter esquecido de deixar o dinheiro após o ato sexual. Nesse momento, já é possível perceber como a prostituição apareceu, desde muito cedo, na vida de Sabrina, como um caminho quase único de sustento. Mais a frente, quando Sabrina encontra sua tia Inês, descobre que ela veio de uma trajetória de prostituição e que sua Mãe também se prostituia antes de se matar para comer durante a gravidez. Com isso, percebemos que a prostituição aparece, na obra, não como uma escolha, mas como um trágico e único caminho pelo qual as mulheres conseguiam se sustentar.

\section{TEMA 6: Saúde Mental}

O tema "Saúde Mental" também perpassa a obra e se materializa, principalmente na figura de Dona Gracinha, avó de Sabrina. Dona Gracinha ficou com o que parece ser uma espécie de demência após a mãe de Sabrina ter se matado. Além desse triste fato, uma queda agravou sua doença e ela passou a ter delírios como ficar pendurando "roupas" que não existiam em um varal. O tema também é abordado quando Sabrina ouve a história de seu avô: após ficar anos trabalhando em um roseiral, ele surta e desaparece. Além desses dois momentos, o tema é abordado também quando a mãe de Sabrina entra em depressão após engravidar dela, aos 15 anos, de um homem comprometido e mais velho que não assumiu a gravidez.

A forma como a autora aborda as temáticas ajuda no processo de reflexão sobre os motivos que levam as pessoas a terem suas mentes adoecidas: um trauma muito forte, como aconteceu com dona gracinha; um abandono, como aconteceu com a mãe de Sabrina ou um excesso de pressão social, como aconteceu com o avô de Sabrina. Possibilita também ao leitor refletir sobre a importância do diálogo para se evitar traumas psicológicos. Exemplo disso é quando Dona Gracinha mostra que parte de sua demência era motivada pela angústia de não ter tido a oportunidade de conversar com sua filha, Maristela, mãe de Sabrina, antes de ela ter se matado.

\section{TEMA 7: Machismo}

O machismo é outro tema que perpassa toda a obra de modo a principalmente mostrar os rastros que ele pode deixar na formação de estruturas familiares e, em âmbito mais específicos, de estruturas psicológicas. Esse tema é abordado, principalmente, nos episódios que retratam a relação de Rodolfo com seu filho Andrea Doria e também com sua esposa, Paloma. A sua rigidez nas palavras e atitudes e a tentativa constante de forçar seu filho e se enquadrar nos padrões esperados pela sociedade para um homem vai desestruturando toda a sua família, pois deixa 
Paloma triste com sua realidade a ponto de decidir não mais viver nela, bem como deixa seu filho, Andrea Doria, distante dele.

\section{TEMA 8: Empoderamento Feminino}

Junto ao machismo ou, contrastando a ele, o livro aborda o tema empoderamento feminino por meio de duas personagens: a tia Inês e Paloma, mãe de Andrea Doria. É interessante destacar que essa abordagem se deu com dois caminhos distintos: (a) um que nos faz pensar sobre o quanto a sociedade ainda não está preparada para receber e/ ou lidar com mulheres empoderadas ou mais que isso, faz-nos pensar sobre os riscos e preços que o empoderamento pode nos trazer nessa sociedade estruturalmente machista e; (b) outro que nos faz ver que, apesar disso, ele ainda é o caminho para a construção da liberdade e poder feminino. O primeiro é representado pela história de Tia Inês, uma mulher que passou parte da vida se prostituindo e mantendo relacionamento com um cafetão do Rio de Janeiro, mas tomou coragem para se libertar dele e reestruturar a vida como professora de dança. Quando conseguiu conquistar sua liberdade, foi baleada e morreu após o cafetão a ter encontrado e tentado forçá-la a voltar a vida antiga. O segundo é representado pela história de Paloma, uma mulher que largou a carreira para dedicar-se à família (marido, casa e filhos), mas só recebia críticas do marido e entrou em um processo de perda da identidade. Então, decidiu separarse dele e realizar seu desejo de adotar Sabrina e Dona Gracinha para constituir sua família, além de retomar sua carreira.

\section{TEMA 9: Dependência Emocional}

O tema dependência emocional também perpassa a obra de várias formas. Uma delas é por meio do retrato à relação amorosa entre Joel e Andrea Doria. Ambos mantinham uma relação desigual, em que Joel usava seu intelecto e idade como instrumento de poder e manipulação de modo a fazer com que Andrea Doria sentisse sempre inferior a ele. Como consequência, Andrea desenvolveu uma série de conflitos psicológicos. Essas consequências foram mais além no caso da relação de Tia Inês com o cafetão que a matou, pois ela deixou todas as suas possibilidades de uma vida melhor (como a de ser dançarina profissional) pelo "amor" que sentia por ele. Ainda mesmo sendo explorada sexualmente, mantevese no relacionamento por muito tempo. Paloma também não fica de fora: deixou sonhos, carreira e a identidade para fazer jus ao que achava ser "amor" pelo marido.

\section{TEMA 10: Gravidez na Adolescência}

O tema gravidez na adolescência aparece quando Sabrina descobre a história de sua mãe, Maristela, a qual ficou grávida aos 15 anos, de um homem mais velho e comprometido. A gravidez não só interrompeu seu sonho de ser professora como também a levou a uma profunda depressão que teve como consequência o suicídio. Interesse destacar que a construção da trajetória dessa personagem leva o leitor a pensar nas consequências psicológicas, financeiras, sociais, etc. da gravidez na adolescência.

\section{TEMA 11: Visões de mundo}

Por fim, o tema "visões de mundo" aparece na obra, principalmente pelo contraste entre a forma como Paloma e Leonardo, seu irmão, enfrentava questões econômicas, ecológicas e sociais e o modo como Rodolfo e a comunidade onde eles moravam faziam. Exemplo disso é um episódio em que Leonardo fala sobre seus planos de embargar a demolição de um monumento histórico e se surpreende ao saber que a comunidade prefere que construa um supermercado no lugar da demolição. Também é possível perceber essa diferença no modo como Paloma vê o mundo: enquanto a comunidade fazia um abaixo-assinado para devolver Sabrina para o orfanato e sua avó para o sanatório e Rodolfo abominava o fato de Sabrina estar se prostituindo, Paloma tinha um olhar diferente: preferiu adotar Sabrina e sua avó e oferecer-lhes oportunidade para trilhar novos caminhos.

\section{Trabalhando com os temas}

Após o levantamento dos temas, a professora criou um evento na plataforma even3, intitulado "Rodas de conversas sobre o livro "Sapato de Salto" e organizou onze atividades, sendo cada uma delas uma roda de conversa sobre um dos temas. A fim de estimular a formação de seus alunos como leitores e também o protagonismo juvenil, a professora convidou entre três e quatro alunos de cada turma para mediarem a discussão de cada roda, cadastrando entre nove e doze alunos como palestrantes convidados em cada atividade do evento. Assim, os estudantes das três turmas 
tiveram de trabalhar juntos, fato que favoreceu 0 trabalho em equipe e a união das turmas.

Após isso, a professora pediu para que as equipes preparassem um folder de divulgação do evento e postassem esse folder em suas redes sociais, a fim de convidar a comunidade a participar do evento. Assim o fizeram e, nesse processo, experienciaram um novo gênero e lidaram com sua forma de circulação: as redes sociais. Feito isso, os estudantes fizeram a leitura da obra. O primeiro capítulo foi lido em voz alta pela professora e os demais foram lidos por eles ora em grupo, ora individualmente.

Nesse momento, o fato de cada um ter um exemplar do livro (disponibilizado pelo PNLD literário) estimulou bastante a leitura. Durante um mês, os estudantes ficaram em posse dos livros e circularam com eles pela escola, disseminando comentários nos corredores e fomentando a discussão a respeito dos temas. Ao mesmo tempo que faziam a leitura, também se preparavam para a discussão da temática pela qual ficaram responsáveis.

A fim de auxiliá-los no trabalho com a modalidade oral da língua e mostrar para os estudantes a complexidade dessa modalidade em situações formais (como era o caso da mediação das rodas de conversa) a professora exigiu que cada equipe organizasse um handout, no qual apresentassem uma breve pesquisa a respeito do estilo da obra e da autora, do tema a ser tratado, com levantamento de especialistas no assunto e também pediu que fizessem uma breve análise dos momentos em que a obra abordava as temáticas.

O projeto gerou um grande impacto na instituição e acabou por mobilizar/interessar não só aos alunos, mas também aos funcionários, pais e comunidade. Durante as discussões, foi possível observar que os estudantes assumiram postura de mediadores do evento e preparam suas falas com suporte teórico. O fato de a professora ter enfatizado, durante todo o processo, que eles seriam responsáveis pelo evento parece ter feito eles viverem o protagonismo pretendido. $O$ grande interesse e a massiva participação no evento (mesmo tendo este acontecido no contraturno) indicia que colocar os estudantes em posição de protagonismo gera interesse nos estudantes.

Quanto à leitura e discussão das temáticas, ao longo das discussões, foi possível notar que houve uma grande identificação dos estudantes com as personagens da obra, especialmente em relação ao tema "descoberta da sexualidade e homoafetividade". Nesse tema em específico, houve controvérsias acentuadas entre as opiniões dos estudantes e de participantes da comunidade mais velhos, mas as discussões embasadas teoricamente auxiliaram os estudantes a encontrarem um caminho empático que os permitissem entender o fundamento histórico das opiniões dos participantes. No geral, todas as temáticas tiveram discussões acaloradas, especialmente porque elas não se esgotam em si, mas auxiliam no processo catártico de construção de identidades e também a pensar nos entornos sociais e psicológicos que envolve cada uma delas.

\section{CONSIDERAÇÕES FINAIS}

Nas considerações iniciais, apresentamos alguns questionamentos que retomamos aqui:(a) quais temas possivelmente difíceis/ polêmicos a obra permite trabalhar? e (b) como abordá-los em um projeto didático-pedagógico que priorize o respeito e a humanização desses temas em prol de uma formação cidadã e, ao mesmo tempo, fortaleça o protagonismo juvenil?

Ao longo do artigo, buscamos responder a essas questões fazendo um levantamento de onze temas que consideramos serem difíceis e/ou polêmicos: (1) abuso sexual infantil; (2) exploração do trabalho infantil; (3) descoberta da sexualidade e homoafetividade; (4) suicídio; (5) prostituição; (6) saúde mental; (7) machismo; (8) empoderamento feminino; (9) dependência emocional; (10) gravidez na adolescência e (11) visões de mundo. Nesse levantamento, pudemos notar que, apesar de difíceis, os temas eram tratados na obra de forma a levar o leitor a entender a constituição histórica, social e psicológica da situação em que a personagem se envolve. Essa construção, a nosso ver, é um instrumento importante de humanização, pois facilita o processo de identificação e empatia. Alguém que abominava a prostituição pode sair da leitura com total empatia pelas prostitutas, pois entende os motivos que as levam à prostituição; alguém que achava que homoafetividade era frescura pode sair da leitura entendendo que não é, pois acompanha os conflitos interiores de Andrea Doria; alguém que achava que depressão é frescura pode sair da leitura entendendo os motivos que levam à depressão e suas graves consequências, por exemplo. Da mesma forma, alguém que estava passando por situações de dependência emocional 
pode se identificar com Paloma e pensar um novo caminho; alguém que estava passando por situações de abuso sexual pode ter, no processo de identificação com Sabrina, o gatilho para denúncia (como aconteceu com uma das estudantes). Enfim, a obra é rica de temas que, se trabalhados de uma forma produtiva e ética, auxiliam na formação humana dos estudantes. Foi justamente essa a intenção do projeto didático-pedagógico que se materializou no evento "Roda de Conversas sobre Sapato de Salto".

Respondendo à segunda pergunta feita no início deste artigo, o caminho que encontramos para abordar os temas de uma forma humanizadora e que estimulasse o protagonismo juvenil foi por meio da criação de um evento mediado pelos alunos. Com a participação da comunidade externa da instituição, os estudantes tiveram de mediar discussões éticas com pessoas de gerações diversas. Esse processo estimulou não só o protagonismo desses estudantes, mas também a empatia e o respeito por opiniões diversas a respeito de uma ou outra temática. Por fim, destacamos que, para além dessas habilidades, os estudantes experienciaram também a imersão linguístico-discursiva em gêneros diversos, dentre os quais destacam-se: handout; folder de divulgação e mediação oral de evento.

\section{REFERÊNCIAS}

BRASIL. Parâmetros Curriculares Nacionais (PCNs). Introdução. Ensino Médio. Brasília. MEC/ SEF, 1988.

BOJUNGA, L. Sapato de salto. Rio de Janeiro: Casa Lygia Bojunga, 2006. 270p.

CRISTÓFANO, S. L. C. O itinerário simbólico em A bolsa amarela de Lygia Bojunga- fantasiar para incluir. Dissertação de Mestrado. Faculdade de Letras/ Universidade do Porto, 2009.

GROSSMAN, E. A construção do Conceito de Adolescência no Ocidente. Educação e Saúde. Rio de Janeiro, v. 7, n. 3, 47-41, 2010.

HENICK, A. C; FARIA, P. M. F. História da Infância no Brasil. In: XVII CONGRESSO NACIONAL DE EDUCAÇÃO, 2005, Anais... p. 25825.

KIRCHOF, E. R. (2014). Literatura Infantil e Diferenças. Educação e realidade, 2-5.
KIRCHOF, E. R.; SOUZA, R. J. (2019). A literatura infantojuvenil na contemporaneidade: desafios, controvérsias e possibilidades. Aberto, Brasília, v. 32, n. 105, 25-40. Disponível em: https://drive. google.com/file/d/1TP34ovZpJmsvF8PN8_ H7BEbpFj4vs_Hn/view. Acesso em: 30 mar. 2019.

MARTHA, A. A. P. Temas e Formas da Narrativa Juvenil Brasileira Contemporânea. In: Simpósio Internacional de Letras e Linguística, 2011.

\section{TEMAS POLÉMICOS EN LA OBRA "ZAPATOS DE TACÓN" DE LYGIA BOJUNGA: UNA EXPERIENCIA PRÁCTICA PARA FOMENTAR LA LECTURA Y EL PROTAGONISMO JUVENIL}

RESUMEN: Paraacompañarlas diversastransformaciones sociales y culturales en el escenario contemporáneo, la escuela ha sentido la necesidad de abordar temas considerados polémicos. En ese escenario, la literatura ha demostrado ser un instrumento importante para atender esta demanda. Este trabajo tiene como objetivo precisamente presentar una práctica docente en la que la obra "Zapatos de Tacón", de Lygia Bojunga (catalogada como literatura infantil y puesta a disposición por el programa literario del PNLD) se utilizó para abordar 11 temas aún considerados controvertidos y / o tabú. A saber: (1) abuso sexual infantil; (2) explotación del trabajo infantil; (3) descubrimiento de la sexualidad y la homoafectividad; (4) suicidio; (5) prostitución; (6) salud mental; (7) machismo; (8) empoderamiento femenino; (9) dependencia emocional; (10) embarazo en la adolescencia; (11) cosmovisiones conservadoras y liberales y (12) prostitución. El trabajo se organizó a través de un evento titulado "Conversaciones sobre el libro Zapatos de Tacón", creado por un docente de la Red Federal de Educación en la plataforma even3. Luego de armar un folleto con investigación científica sobre los temas y de haber hecho un breve análisis del trabajo enfocándose en cada tema, 120 estudiantes de tres clases de primer año de secundaria invitaron a la comunidad a inscribirse en el evento y lideraron discusiones sobre los temas. Durante la actividad, los estudiantes destacaron la importancia de los espacios de discusión sobre estos temas y propusieron la creación de nuevos proyectos y actividades relacionadas con los temas. En general, la actividad nos hizo observar que acciones como estas cumplen con los objetivos del BNCC y otros documentos oficiales, ya que, además de estimular el protagonismo juvenil, es un paso importante en la formación de los estudiantes como lectores y ciudadanos.

Palabras clave: Literatura Infantil y Juvenil; Protagonismo Juvenil; Temas Polémicos. 